\title{
Association of informal caregiving with body mass index and frequency of sporting activities: evidence of a population-based study in Germany
}

\author{
André Hajek* ${ }^{*}$, Jens-Oliver Bock and Hans-Helmut König
}

\begin{abstract}
Background: While most studies focused solely on the comparison between informal caregivers and non-caregivers, little is known about the relation between caregiving time or caregiving activities and lifestyle factors. Thus, the aim of this study was to examine whether informal caregiving time and type of caregiving activities are associated with body mass index (BMI) and the frequency of sporting activities among informal caregivers.

Methods: Cross-sectional data were gathered from the German Ageing Survey, a nationally representative study among community-dwelling individuals aged $\geq 40$ that includes a total of $n=1380$ people who provide informal care services. Self-reported BMI and self-reported frequency of sporting activities (daily; several times a week; once a week; 1-3 times a month; less often; never) were used as dependent variables. The average time of providing informal care per week as well as four different caregiving activities (help around the house; looking after someone; performing nursing care services; help in another way) were included as independent variables. Multiple ordinal and linear regressions were used to estimate the association between caregiving factors and the frequency of sporting activities and BMI, respectively.

Results: Among the 1380 informal caregivers, 65\% provided help around the house, 83\% looked after people, 28\% provided nursing care services, and 68\% provided any other help. Bivariate analyses showed that sporting activities and BMI differed by status of providing nursing care services, whereas the other three types of informal caregiving were not associated with BMI nor frequency of sporting activities except for the latter and provision of help around the house. Multiple regressions showed that BMI increased with caregiving time and performing nursing care services, whereas it was not associated with the other three caregiving activities. Likewise, the frequency of sporting activities decreased only with caregiving time and performing nursing care services.

Conclusions: The present study revealed that caregiving time and performing nursing care services are associated with a higher BMI and a decreased frequency of sporting activities. As both, a higher BMI and fewer sporting activities are in turn related to various adverse health outcomes, this knowledge should be taken into account when planning informal caregiving.
\end{abstract}

Keywords: Informal care, Sports, Body-mass-index, Observational study

\footnotetext{
* Correspondence: a.hajek@uke.de

Department of Health Economics and Health Services Research, Hamburg

Center for Health Economics, University Medical Center Hamburg-Eppendorf,

Hamburg, Germany
} 


\section{Background}

Maintaining familiar surroundings or keeping social ties are main reasons why most people in need for care prefer to live at home as long as possible [1] where most of the required care is provided informally by family members [2]. Due to demographic aging, it is projected that the need for informal care will rise considerably in the upcoming decades, underlining the relevance of informal caregiving. Nevertheless, various studies have found that informal caregiving is associated with adverse outcomes, such as reduced satisfaction with life or mental health [3-5]. However, little is known about the relationship between informal caregiving and lifestyle factors such as body mass index (BMI) or frequency of sporting activities. An increased BMI is, for example, a risk factor for various cardiovascular diseases [6]. Sporting activities are protective against various adverse health outcomes [7]. Yet, this relationship might be worth investigating, since providing informal care limits the time disposable and motivation for doing sports.

For example, using data from the Behavioral Risk Factor Surveillance System (BRFSS), which is a nationally representative survey of the civilian, non-institutionalized, adult population ( $\geq 18$ years) in the USA, Do et al. [8] found individuals who provided informal care to have a slightly higher BMI than those who do not. Also based on a US sample, Kusano et al. [9] showed that informal caregivers who suffered from a financial burden were more likely to be overweight and obese than the non-caregiving comparison group. Equally, Lee et al. [10] reported higher BMI rates for people who care for their spouses or parents as compared to a control group who do not. Moreover, Hoffman et al. [11] investigated sedentary behavior of caregivers and noncaregivers. Concerning sedentary behavior, they found that the percentages were similar in both groups.

While most studies focused solely on the comparison between informal caregivers and non-caregivers, little is known about the relation between caregiving time or caregiving activities and lifestyle factors. This knowledge is important to reveal further insights into the relation between conditions of informal care and these outcome measures. Hence, the aim of the present study was to determine whether caregiving time and caregiving activities are associated with two outcome measures ((1) BMI and the (2) frequency of sporting activities) among informal caregivers using a representative sample of communitydwelling individuals in the second half of life (aged 40 and over) in Germany. Thus, our aim was twofold: First, to study the association between caregiving time as well as caregiving activities and BMI. Second, to study the association between caregiving as well as caregiving activities and frequency of sporting activities.

It is important to know whether informal caregiving time is associated with, e.g., restrictions in the frequency of sporting activities and an increased BMI because this might help to identify caregivers at risk for an unhealthy lifestyle. This unhealthy lifestyle is in turn associated with morbidity and mortality $[12,13]$. In addition, it is important to know which caregiving activities are associated with BMI as well as the frequency of sporting activities as this may reveal which caregiving tasks pose a particular challenge for individuals providing informal care.

\section{Methods \\ Sample}

Cross-sectional data from the fifth wave of the German Ageing Survey (Deutscher Alterssurvey; DEAS) were used. DEAS is an ongoing longitudinal, population-based study of the German community-dwelling population in the second half of life (40 years and over) started in 1996. The sample was drawn by means of national probability sampling and was systematically stratified by region (West and East Germany), age and gender. Follow-up waves took place in 2002 (second wave), 2008 (third wave), 2011 (fourth wave), and 2014 (fifth wave). Each wave comprised a panel-sample (participants who had already been interviewed) and a new cross-sectional sample, except for 2011, which was a pure panel survey. Face-to-face interviews are conducted in each wave. After the oral interview, respondents are asked to fill out an additional written questionnaire (so called 'drop-off' self-report questionnaire). Please see for further details Klaus et al. [14].

In the fifth wave, about 6000 participants were interviewed for the first time (response rate: $25 \%$ ) while over 4000 participants had already been interviewed in former waves (response rate: $61 \%$ ). In total, the response rate corresponds to that in other large German survey studies [15]. Out of the 10,324 participants in the fifth wave, the subsample of $n=1380$ who provided informal care and filled out the 'drop-off' self-report questionnaire including, e.g., psychological scales and physical (chronic) illnesses, was used for the present analysis.

Please note that an ethical statement for the DEAS study was not necessary because criteria for the need of an ethical statement were not met (risk for the respondents, lack of information about the aims of the study, examination of patients).

\section{Dependent variables: Body-mass-index and frequency of sporting activities}

The BMI was computed from self-reported height (meter) and weight $(\mathrm{kg})$ as weight divided by height-squared. In adults, the BMI is widely used as a body weight classification system (e.g., for excess weight). Furthermore, individuals were asked "How often do you do sports such as hiking, soccer, gymnastics, or swimming?” (daily; several times a week; once a week; 1-3 times a month; less often; never). The frequency format is based on the International 
Physical Activity Questionnaire (IPAQ) [16]. Furthermore, the item used in our study was validated [17].

In additional analysis, the frequency of sporting activities was replaced by three different outcomes; including frequency of ... (1) strenuous physical activities, (2) moderate physical activities, and (3) light physical activities. Again, the frequency format was: daily; several times a week; once a week; 1-3 times a month; less often; never.

The exact wording was as follows:

- "How often do you do strenuous physical activities? What is meant here are activities that require great physical efforts and whereby you breathe more heavily than normal, e.g. carrying heavy loads, arduous gardening, aerobic or fast cycling. Please include all strenuous physical activities, those within your work, in the household and in the garden, in order to get from one place to another and in your spare time."

- "How often do you do moderate physical activities? What is meant here are activities that require moderate physical efforts whereby you breathe a bit more heavily than normal, e.g. carrying light loads, easy gardening, hiking, swimming or cycling with normal speed. Please include all moderate physical activities, those within your work, in the household and in the garden, in order to get from one place to another and in your spare time. Please don't include walks."

- "How often do you do light physical activities? What is meant here are activities that require little physical efforts whereby you don't breathe more heavily than normal, e.g. walking around at home, walks from one place to another as well as walks that you do for relaxation, as sport, as training or just for pleasure."

\section{Main independent variables: Informal caregiving activities and caregiving time}

Individuals were asked if they provide informal care with the question: "Are there people you look after or care for regularly due to their poor state of health, either on a private or volunteer basis?" (no; yes). Among those informal caregivers, individuals were asked (yes; no) "What kind of care or assistance do you provide to the person who you help? A: Do you help around the house? B: Do you look after him/her or keep him/her company? C: Do you perform care services for the person you assist? D: Do you help in another way?" In a narrow sense, care can be seen as "nursing care" (C: "Do you perform care services for the person you assist?").

Furthermore, informal caregivers should rate how much time they spend per week providing informal care (average number of hours per week, ranging from 0 to $168 \mathrm{~h}$ ).

It is worth noting that the respondents were also asked 'Who do you assist in this way?' (Possible to name up to three persons). However, which is also worth emphasizing, our main independent variables (informal caregiving activities and caregiving time) refer to the person who the caregiver help the most.

\section{Independent variables: Potential confounders}

Based on theoretical considerations and previous findings the following socioeconomic variables were included in the regression analysis: Age, sex, family status (distinguishing between: married and living together with spouse; others (married and living separately, divorced, widowed, and single)), occupational status (employed, retired, other), and individual monthly net equivalent income (OECD scale). Moreover, the sum of physical illnesses (e.g., insomnia, eye problems, ear problems, cardiac and circulatory disorders or cancer; ranging from 0 to 11) was used as covariate. For example, it has been shown that age is associated with physical activities [18]. Furthermore, it has been shown that BMI is positively associated with younger age [19]. Moreover, it has been found that employment status is associated with physical activity [20]. In addition, it has been demonstrated that (1) cardiac and circulatory disorders, (2) respiratory problems, asthma, shortness of breath, (3) stomach and intestinal problems, (4) cancer, and (5) gall bladder, liver or kidney problems are associated with weight loss [21, 22].

\section{Statistical analysis}

First, descriptive sample statistics were computed. Second, multiple ordinal (ordered probit, with frequency of sports activities as outcome variable) and linear regressions (with BMI as outcome variable) were estimated, adjusting for potential confounders. The statistical significance was determined with $p<0.05$. Stata 14.0 (StataCorp, College Station, Texas, USA) was used to conduct statistical analyses.

\section{Results}

\section{Sample characteristics}

Table 1 shows the sample characteristics stratified by type of informal caregiving. Among the caregivers, $65.1 \%$ provided help around the house, $83.2 \%$ looked after their relative, $27.9 \%$ provided nursing care services, and $67.9 \%$ provided any other type of help. The mean age of all informal caregivers was 63.4 years (SD: 10.4 years) with a range from 40 to 91 years. $60.0 \%$ were female.

The BMI was $26.8 \mathrm{~kg} / \mathrm{m}^{2}$ (SD: $4.5 \mathrm{~kg} / \mathrm{m}^{2}$ ) on average. As Table 1 displays, there was a statistical significant difference between caregivers who provide nursing care services as 


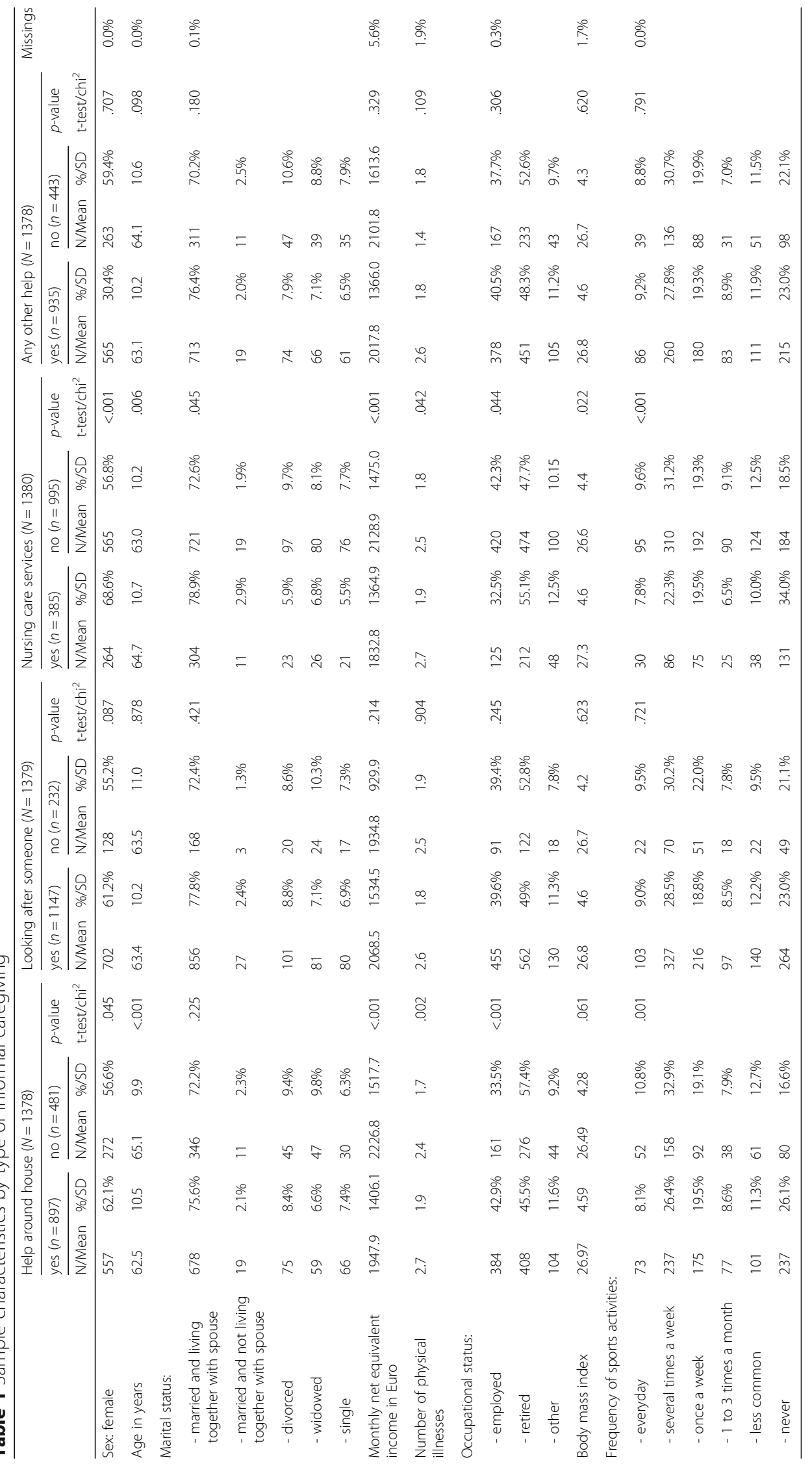


compared to those who only provide other types of informal care; the BMI of the group providing nursing care services was about $0.7 \mathrm{~kg} / \mathrm{m}^{2}$ higher than the BMI of the group not providing nursing care services. Equally, there was a significant deviation in the frequency of doing sports between both aforementioned groups. Additionally, the frequency of doing sports deviated between the groups who provided help around the house and those who did not. With respect to other types of informal caregiving, there were no significant differences regarding frequency of doing sporting activities and BMI.

Table 2 splits the sample by the median of informal caregiving time per week. The median was $5 \mathrm{~h}$ per week and people who provided informal care of exactly $5 \mathrm{~h}$ per week were assigned to the group below the median so that this group is larger with $n=732$ participants compared to $n=604$ participants above the median. The latter group above the median was more likely to be female and somewhat older. In addition, there were significant differences in all considered potentially confounding variables. The BMI was significantly higher in the group that provided care more than $5 \mathrm{~h}$ per week. Besides, the frequency of doing sports deviated significantly between the two groups.

\section{Multiple regression analysis}

Table 3 displays the results of the multiple regression analyses with the BMI as dependent variable. Model 1 to 4 (marked as (1), (2), (3), and (4) in Table 3)) include the types of informal caregiving, model 5 (marked as (5) in Table 3) the time of informal caregiving per week. The same principle holds for Table 4. All models are fully adjusted for the various potential confounders (sex, age, marital status, number of illnesses, income, and occupational status). The regression models showed no association of BMI with three out of the four types of informal caregiving. Only the provision of nursing care services was associated with an increased BMI of about $0.6 \mathrm{~kg} / \mathrm{m}^{2}$. For example, for an individual of $1.70 \mathrm{~m}$ height performing nursing care services this increase in BMI equals an increase in weight of about $1.68 \mathrm{~kg}$ (ceteris paribus). Spending more time on providing informal care was associated with an increased BMI; each additional hour per week was associated with a higher BMI of about $0.01 \mathrm{~kg} / \mathrm{m}^{2}$.

With respect to the control variables, female gender, the number of illnesses, and net equivalent income per capita were positively associated with the BMI, whereas a higher age was negatively associated with the BMI in all five models.

Table 2 Sample characteristics by the time spent on informal caregiving per week (median split)

\begin{tabular}{|c|c|c|c|c|c|c|}
\hline & \multicolumn{4}{|c|}{ Time spent on informal caregiving per week $(N=1336)$} & \multirow{3}{*}{$\begin{array}{l}p \text {-value } \\
\text { t-test/chi }\end{array}$} & \multirow{3}{*}{ Missings } \\
\hline & \multicolumn{2}{|c|}{$\leq 5 \mathrm{~h}(n=732)$} & \multicolumn{2}{|c|}{$>5 \mathrm{~h}(n=604)$} & & \\
\hline & N/Mean & $\% / S D$ & N/Mean & $\% / S D$ & & \\
\hline Sex: female & 422 & $57.7 \%$ & 382 & $63.3 \%$ & .038 & $0.0 \%$ \\
\hline Age in years & 62.1 & 10.2 & 64.5 & 10.3 & $<.001$ & $0.0 \%$ \\
\hline \multicolumn{7}{|l|}{ Marital status: } \\
\hline - married and living together with spouse & 519 & $71.0 \%$ & 473 & $78.4 \%$ & .001 & $0.1 \%$ \\
\hline - married and not living together with spouse & 11 & $1.5 \%$ & 18 & $2.9 \%$ & & \\
\hline - divorced & 81 & $11.1 \%$ & 37 & $6.1 \%$ & & \\
\hline - widowed & 66 & $9.0 \%$ & 37 & $6.1 \%$ & & \\
\hline - single & 54 & $7.4 \%$ & 38 & $6.3 \%$ & & \\
\hline Monthly net equivalent income in Euro & 2179.1 & 1494.6 & 1899.8 & 1420.6 & $<.001$ & $5.6 \%$ \\
\hline Number of physical illnesses & 2.3 & 1.7 & 2.8 & 1.9 & $<.001$ & $1.9 \%$ \\
\hline \multicolumn{7}{|l|}{ Occupational status: } \\
\hline - employed & 349 & $47.7 \%$ & 193 & $31.9 \%$ & $<.001$ & $0.3 \%$ \\
\hline - retired & 321 & $43.9 \%$ & 329 & $54.5 \%$ & & \\
\hline - other & 61 & $8.3 \%$ & 82 & $13.6 \%$ & & \\
\hline Body mass index & 26.5 & 4.2 & 27.3 & 4.7 & .001 & $1.7 \%$ \\
\hline Sport: - daily & 73 & $10.0 \%$ & 48 & $7.9 \%$ & $<.001$ & $0.0 \%$ \\
\hline - more than once a week & 257 & $35.1 \%$ & 128 & $21.2 \%$ & & \\
\hline - once a week & 140 & $19.1 \%$ & 123 & $20.4 \%$ & & \\
\hline - 1-3 times a month & 65 & $8.9 \%$ & 49 & $8.1 \%$ & & \\
\hline - less than 1-3 times a month & 83 & $11.3 \%$ & 72 & $11.9 \%$ & & \\
\hline - never & 114 & $15.6 \%$ & 184 & $30.5 \%$ & & \\
\hline
\end{tabular}


Table 3 Multiple linear regression analyses with body mass index as dependent variable

\begin{tabular}{|c|c|c|c|c|c|}
\hline \multirow[b]{2}{*}{ Independent variables } & (1) & (2) & (3) & (4) & (5) \\
\hline & \multicolumn{5}{|c|}{ Dependent variable: body mass index (BMI) } \\
\hline \multirow[t]{2}{*}{ Sex: female (Ref:: male) } & $-0.908^{* * *}$ & $-0.919^{* * *}$ & $-0.967^{* * *}$ & $-0.925^{* * *}$ & $-1.001^{* * *}$ \\
\hline & $(0.251)$ & $(0.252)$ & $(0.253)$ & $(0.250)$ & $(0.255)$ \\
\hline \multirow[t]{2}{*}{ Age in years } & $-0.043^{*}$ & $-0.043^{*}$ & $-0.045^{*}$ & $-0.044^{*}$ & $-0.039+$ \\
\hline & $(0.021)$ & $(0.021)$ & $(0.021)$ & $(0.021)$ & $(0.021)$ \\
\hline \multirow{2}{*}{$\begin{array}{l}\text { Marital status: - married, not living together with spouse } \\
\text { (Ref.: married and living together with spouse) }\end{array}$} & -0.518 & -0.526 & -0.563 & -0.502 & -0.562 \\
\hline & $(0.774)$ & $(0.774)$ & $(0.781)$ & $(0.775)$ & $(0.780)$ \\
\hline \multirow[t]{2}{*}{ - divorced } & -0.764 & $-0.832+$ & -0.697 & $-0.823+$ & -0.690 \\
\hline & $(0.472)$ & $(0.471)$ & $(0.472)$ & $(0.471)$ & $(0.476)$ \\
\hline \multirow[t]{2}{*}{ - widowed } & 0.373 & 0.407 & 0.419 & 0.278 & 0.384 \\
\hline & $(0.481)$ & $(0.485)$ & $(0.481)$ & $(0.477)$ & $(0.482)$ \\
\hline \multirow[t]{2}{*}{ - single } & -0.128 & -0.155 & -0.130 & -0.294 & 0.0773 \\
\hline & $(0.608)$ & $(0.602)$ & $(0.602)$ & $(0.597)$ & $(0.622)$ \\
\hline \multirow[t]{2}{*}{ Number of illnesses } & $0.461^{* * *}$ & $0.470^{* * *}$ & $0.459^{* * *}$ & $0.473^{* * *}$ & $0.455^{* * *}$ \\
\hline & $(0.078)$ & $(0.077)$ & $(0.077)$ & $(0.076)$ & $(0.078)$ \\
\hline \multirow[t]{2}{*}{ Mean monthly net equivalent income } & $-0.359^{* * *}$ & $-0.366^{* * *}$ & $-0.350^{* * *}$ & $-0.370^{* * *}$ & $-0.378^{* * *}$ \\
\hline & $(0.088)$ & $(0.089)$ & $(0.085)$ & $(0.090)$ & $(0.079)$ \\
\hline \multirow[t]{2}{*}{ Occupational status: - retired (Ref.: employed) } & 0.148 & 0.125 & 0.102 & 0.128 & 0.0376 \\
\hline & $(0.440)$ & $(0.439)$ & $(0.436)$ & $(0.437)$ & $(0.437)$ \\
\hline \multirow[t]{2}{*}{ - others } & 0.322 & 0.316 & 0.300 & 0.359 & 0.184 \\
\hline & $(0.506)$ & $(0.506)$ & $(0.504)$ & $(0.505)$ & $(0.506)$ \\
\hline \multirow[t]{2}{*}{ Help around house: yes (Ref.: no) } & 0.132 & & & & \\
\hline & $(0.259)$ & & & & \\
\hline \multirow[t]{2}{*}{ Looking after someone: yes (Ref.: no) } & & 0.285 & & & \\
\hline & & $(0.319)$ & & & \\
\hline \multirow[t]{2}{*}{ Nursing care services: yes (Ref.: no) } & & & $0.580^{*}$ & & \\
\hline & & & $(0.294)$ & & \\
\hline \multirow[t]{2}{*}{ Any other help: yes (Ref:: no) } & & & & 0.020 & \\
\hline & & & & $(0.255)$ & \\
\hline \multirow[t]{2}{*}{ Time per week spent for informal care (in hours) } & & & & & $0.013^{*}$ \\
\hline & & & & & $(0.006)$ \\
\hline \multirow[t]{2}{*}{ Constant } & $29.52^{* * *}$ & $29.36^{* * *}$ & $29.59^{* * *}$ & $29.61^{* * *}$ & $29.37^{* * *}$ \\
\hline & $(1.173)$ & $(1.163)$ & $(1.157)$ & $(1.190)$ & $(1.181)$ \\
\hline Observations & 1,256 & 1,257 & 1,257 & 1,256 & 1,221 \\
\hline$R^{2}$ & 0.064 & 0.065 & 0.066 & 0.066 & 0.068 \\
\hline
\end{tabular}

Comments: Beta-coefficients were reported. Cluster-robust standard errors in parentheses

${ }^{* * *} p<0.001$

${ }^{* *} p<0.01$

${ }^{*} p<0.05,+p<0.10$

The results of multiple ordered probit regression analyses with frequency of doing sporting activities are depicted in Table 4. Help around the house was associated with a lower frequency of doing sports activities (model (1)) after adjustment of the covariates. Equally, providing nursing care services was associated with doing fewer sporting activities (model (3)). The informal caregiving types of 'looking after someone' and 'any other help' were not associated with the frequency of doing sporting activities (models (2) and (4)). With respect to the time spent on informal caregiving, each additional hour spent on informal caregiving was associated with a lower frequency of sporting activities (model (5)). 
Table 4 Multiple ordered probit regression analyses with frequency of sports activities per week as dependent variable

\begin{tabular}{|c|c|c|c|c|c|}
\hline \multirow{2}{*}{ Independent variables } & (1) & (2) & (3) & (4) & (5) \\
\hline & \multicolumn{5}{|c|}{ Dependent variable: Frequency of sports activities } \\
\hline \multirow[t]{2}{*}{ Sex: female (Ref:: male) } & $0.121+$ & $0.110+$ & $0.149^{*}$ & $0.110+$ & $0.166^{* *}$ \\
\hline & $(0.063)$ & $(0.063)$ & $(0.063)$ & $(0.063)$ & $(0.064)$ \\
\hline \multirow[t]{2}{*}{ Age in years } & $-0.012^{*}$ & $-0.011^{*}$ & $-0.010^{*}$ & $-0.011^{*}$ & -0.008 \\
\hline & $(0.005)$ & $(0.005)$ & $(0.005)$ & $(0.005)$ & $(0.005)$ \\
\hline \multirow{2}{*}{$\begin{array}{l}\text { Marital status: - married, not living together with spouse } \\
\text { (Ref:: married and living together with spouse) }\end{array}$} & 0.0756 & 0.0778 & 0.0956 & 0.0716 & 0.204 \\
\hline & $(0.203)$ & $(0.203)$ & $(0.204)$ & $(0.203)$ & $(0.102)$ \\
\hline \multirow[t]{2}{*}{ - divorced } & 0.139 & 0.159 & 0.122 & 0.156 & 0.204 \\
\hline & $(0.107)$ & $(0.107)$ & $(0.107)$ & $(0.107)$ & $(0.073)$ \\
\hline \multirow[t]{2}{*}{ - widowed } & -0.119 & -0.0895 & -0.123 & -0.0830 & 0.108 \\
\hline & $(0.116)$ & $(0.116)$ & $(0.116)$ & $(0.116)$ & $(-0.179)$ \\
\hline \multirow[t]{2}{*}{ - single } & $-0.216+$ & $-0.205+$ & $-0.219+$ & $-0.214+$ & 0.118 \\
\hline & $(0.117)$ & $(0.117)$ & $(0.117)$ & $(0.117)$ & $(-0.217)$ \\
\hline \multirow[t]{2}{*}{ Number of illnesses } & $-0.050^{* *}$ & $-0.055^{* *}$ & $-0.055^{* *}$ & $-0.056^{* *}$ & $-0.048^{* *}$ \\
\hline & $(0.018)$ & $(0.017)$ & $(0.017)$ & $(0.017)$ & $(0.018)$ \\
\hline \multirow[t]{2}{*}{ Mean monthly net equivalent income } & $0.068^{* *}$ & $0.075^{* * *}$ & $0.068^{* *}$ & $0.074^{* * *}$ & $0.076^{* * *}$ \\
\hline & $(0.021)$ & $(0.021)$ & $(0.021)$ & $(0.021)$ & $(0.021)$ \\
\hline \multirow[t]{2}{*}{ Occupational status: - retired (Ref:: employed) } & 0.154 & $0.169+$ & $0.181+$ & $0.173+$ & 0.208 \\
\hline & $(0.101)$ & $(0.101)$ & $(0.101)$ & $(0.101)$ & $(0.102)$ \\
\hline \multirow[t]{2}{*}{ - others } & -0.113 & -0.113 & -0.102 & -0.113 & -0.065 \\
\hline & $(0.107)$ & $(0.107)$ & $(0.107)$ & $(0.107)$ & $(0.109)$ \\
\hline \multirow[t]{2}{*}{ Help around house: yes (Ref.: no) } & $-0.225^{* * *}$ & & & & \\
\hline & $(0.063)$ & & & & \\
\hline \multirow[t]{2}{*}{ Looking after someone: yes (Ref.: no) } & & -0.062 & & & \\
\hline & & $(0.080)$ & & & \\
\hline \multirow[t]{2}{*}{ Nursing care services: yes (Ref.: no) } & & & $-0.284^{* * *}$ & & \\
\hline & & & $(0.068)$ & & \\
\hline \multirow[t]{2}{*}{ Any other help: yes (Ref:: no) } & & & & -0.024 & \\
\hline & & & & $(0.064)$ & \\
\hline \multirow[t]{2}{*}{ Time per week spent for informal care (in hours) } & & & & & $-0.011^{* * *}$ \\
\hline & & & & & $(0.002)$ \\
\hline \multirow[t]{2}{*}{ Constant cut1 } & $-1.511^{* * *}$ & $-1.333^{* * *}$ & $-1.312^{* * *}$ & $-1.313^{* * *}$ & $-1.189^{* * *}$ \\
\hline & $(0.281)$ & $(0.280)$ & $(0.275)$ & $(0.279)$ & $(0.280)$ \\
\hline \multirow[t]{2}{*}{ Constant cut2 } & $-1.141^{* * *}$ & $-0.966^{* * *}$ & $-0.941^{* * *}$ & $-0.945^{* * *}$ & $-0.814^{* *}$ \\
\hline & $(0.280)$ & $(0.278)$ & $(0.273)$ & $(0.278)$ & $(0.279)$ \\
\hline \multirow[t]{2}{*}{ Constant cut3 } & $-0.913^{* *}$ & $-0.739^{* *}$ & $-0.713^{* *}$ & $-0.720^{* *}$ & $-0.577^{*}$ \\
\hline & $(0.280)$ & $(0.278)$ & $(0.273)$ & $(0.278)$ & $(0.279)$ \\
\hline \multirow[t]{2}{*}{ Constant cut4 } & -0.416 & -0.245 & -0.217 & -0.224 & -0.066 \\
\hline & $(0.279)$ & $(0.278)$ & $(0.273)$ & $(0.277)$ & $(0.279)$ \\
\hline \multirow[t]{2}{*}{ Constant cut5 } & $0.617^{*}$ & $0.790^{* *}$ & $0.820^{* *}$ & $0.809^{* *}$ & $0.982^{* * *}$ \\
\hline & $(0.281)$ & $(0.280)$ & $(0.275)$ & $(0.279)$ & $(0.281)$ \\
\hline Observations & 1273 & 1274 & 1275 & 1273 & 1236 \\
\hline Pseudo $R^{2}$ & 0.014 & 0.011 & 0.016 & 0.012 & 0.021 \\
\hline
\end{tabular}

Comments: Coefficients were reported (larger values correspond to "higher" outcomes). 95\% confidence intervals in parentheses

${ }^{* * *} p<0.001$

${ }^{* *} p<0.01$

${ }^{*} p<0.05,+p<0.10$ 
Regarding the control variables, a higher number of illness was associated with a lower frequency of doing sports in all five models, and higher net equivalent income per capita was associated with higher frequency.

In additional analysis (please see Additional file 1: Tables S1, Additional file 2: Tables S2 and Additional file 3: Tables S3), the frequency of sporting activities was replaced by the frequency of (1) light (2) moderate, and (3) strenuous physical activities. While providing nursing care services and caregiving time were associated with the frequency of light physical activities, only caregiving time was significantly associated with the frequency of moderate physical activities. In contrast, none of the caregiving factors was associated with the frequency of strenuous physical activities.

\section{Discussion}

\section{Main findings}

Using a representative sample of individuals in the second half of life, this study aimed at examining whether caregiving time and caregiving activities are associated with BMI and the frequency of sporting activities. The results show that the BMI increased with caregiving time and performing nursing care services, whereas it was not associated with the other caregiving activities (help around house; looking after someone; any other help). Equally, the frequency of sporting activities decreased with caregiving time and performing nursing care services, whereas the outcome measure was not associated with the other caregiving activities (except for help around house). Additional analysis showed that nursing care services were only associated with the frequency of light physical activities, whereas it was neither significantly associated with moderate nor with strenuous physical activities.

\section{Previous research}

While several studies examined whether informal caregivers and non-caregivers differ in lifestyle factors $[11,23]$, little is known about the associations between caregiving time as well as caregiving activities with lifestyle factors among informal caregivers. For example, it was found that $26.1 \%$ of full-time informal caregivers were obese compared with $22.6 \%$ of part-time informal caregivers in Thailand $(n=60,569)$ [24]. In addition, it has been shown that women providing care to an ill/disabled spouse had a higher BMI (mean BMI was 27.0) compared to women providing care to an ill parent/ill others (both, with mean BMI of 26.1) in 11 states of the USA $(n=54,411)[10]$. However, physical activity (metabolic equivalent hours (MET-hours) per week) was similar between women providing care to an ill/disabled spouse and women providing care to an ill parent.

Our study adds further insights into the relationship between these lifestyle factors and informal caregiving time as well as several caregiving activities. The current study showed that the BMI is positively associated with caregiving time and performing nursing care services, whereas it was not associated with the other caregiving activities. A possible explanation might be that long caregiving time as well as performing nursing care services are associated with adverse factors such as stress or depressive symptoms [3] because (1) informal caregivers are generally not used to perform nursing caregiving activities and because (2) an increase in informal caregiving time is often the result of an increase in cognitive impairment of care-recipients [25]. This is supported by the fact that according to our calculations (German Ageing Survey, fifth wave), caregiving time was associated with increased depressive symptoms [26] $(r=.19, p<.001)$ and increased stress [27] $(r=.16, p<.001)$. These factors including depressive symptoms are in turn associated with a higher BMI [28] or a reduced frequency of physical activities [29].

Likewise, the frequency of sporting activities decreased with caregiving time and performing nursing care services, whereas it was not associated with the other caregiving activities. In the German Ageing Survey (fifth wave), the evaluation of leisure time (ranging from 1 $=$ "very bad" to $5=$ "very good") was associated with caregiving time $(r=-.30, p<.001)$. This might support the idea that an increase in caregiving time restricts leisure time. Furthermore, performing nursing care activities might be a source of stress, which might exhaust individuals' resources. This is supported by the fact that performing nursing care services was associated with increased perceived stress $(r=.13, p<.001)$ in the German Ageing Survey (fifth wave).

Thus, individuals might have a lack of energy or they might be too tired to exercise. However, this is speculative and consequently should be investigated in future studies. It should be acknowledged that caregiving time and performing nursing care services were only weakly associated with both outcome measures. For example, the partial $\eta^{2}$ for these two explanatory variables was .003 each $(0.3 \%$ of the variability in BMI explained) in the models presented in column 3 and column 5 of Table 3. Consequently, the clinical significance might be limited or even small.

In contrast to performing nursing care activities, the other caregiving activities (except for help around house) might have a stronger focus on supervision or are strongly related to everyday household activities. In many cases, informal caregivers might be familiar with these activities, which might help to cope with the demands of informal care. Thus, it is assumed that individuals did not perceive the other caregiving activities as demanding, stressful or challenging. Consequently, it appears plausible that the other caregiving activities are not associated with both outcome measures. 


\section{Strengths and limitations}

This is one of few studies providing insights into the relationship between informal caregiving time, caregiving activities and the lifestyle factors of BMI and sporting activities. Data from the present study were gathered from a large, population-based study among community-dwelling individuals aged 40 and over. Data on caregiving time as well as on four caregiving activities were provided. A limitation of the study is that we cannot exclude a potential recall bias in participants' estimations of average caregiving time. Thus, it is also likely that self-reported BMI is biased downwards because subjects generally tend to underestimate weight and overestimate height [30]. In addition, this study is cross-sectional, which does not allow analyzing the causal inference of the variables of interest. Thus, we cannot dismiss the possibility that changes in body mass index (BMI) and changes in the frequency of sporting activities affect the probability of starting informal caregiving. However, we assume that this is rarely the case.

Moreover, because a sample selection bias cannot be ruled out, our findings might be difficult to generalize to individuals with, e.g., low education. However, it has been shown that selectivity effects were rather small in the DEAS study [31].

\section{Conclusion}

The present study revealed that caregiving time and performing nursing care services are associated with a higher BMI and a decreased frequency of sporting activities. As both, a higher BMI and fewer sporting activities are in turn related to various adverse health outcomes (including morbidity and mortality), this knowledge should be taken into account by policy makers when planning and promoting informal caregiving. For example, the provision of shortterm accommodation (respite care) might be fruitful in reducing symptoms of stress in informal caregivers [32]. Future research is required to disentangle the immediate impact of informal caregiving on physical activities and the long-term impact on BMI (which might be mediated by physical activities).

\section{Additional files}

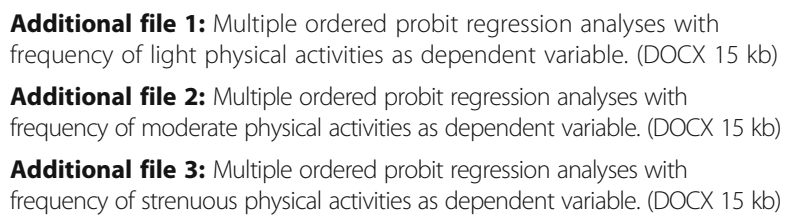

\section{Abbreviations}

BMI: body mass index; BRFSS: Behavioral Risk Factor Surveillance System; DEAS: German Ageing Survey; OECD: Organization for Economic Co-Operation and Development

\section{Acknowledgements}

Not applicable.

Funding

None.

\section{Availability of data and materials}

The data used in this study are third-party data. The anonymized data sets of the DEAS $(1996,2002,2008,2011$, and 2014) are available for secondary analysis. The data has been made available to scientists at universities and research institutes exclusively for scientific purposes. The use of data is subject to written data protection agreements. Microdata of the German Ageing Survey (DEAS) is available free of charge to scientific researchers for non-profitable purposes. The FDZ-DZA provides access and support to scholars interested in using DEAS for their research. However, for reasons of data protection, signing a data distribution contract is required before data can be obtained. Please see for further Information (data distribution

contract): https:/www.dza.de/en/fdz/access-to-data/formular-deas-en-english.html.

\section{Authors' contributions}

$\mathrm{AH}, \mathrm{JOB}, \mathrm{HHK}$ : Design and concept of analyses, preparation of data, statistical analysis and interpretation of data, preparing of the manuscript. All authors critically reviewed the manuscript, provided significant editing of the article and approved the final manuscript.

\section{Ethics approval and consent to participate}

Please note that an ethical statement for the DEAS study was not necessary because criteria for the need of an ethical statement were not met (risk for the respondents, lack of information about the aims of the study, examination of patients).

Prior to the interview, written informed consent was given by all participants of the study.

Consent for publication

Not applicable.

Competing interests

The authors declare that they have no competing interests.

\section{Publisher's Note}

Springer Nature remains neutral with regard to jurisdictional claims in published maps and institutional affiliations.

Received: 19 July 2017 Accepted: 21 September 2017

Published online: 29 September 2017

\section{References}

1. Heuchert M, König H-H, Lehnert T. Die Rolle von Präferenzen für Langzeitpflege in der sozialen Pflegeversicherung-Ergebnisse von Experteninterviews. Gesundheitswesen. 2016. p. 1-6.

2. Hajek A, Lehnert T, Wegener A, Riedel-Heller SG, König H-H. Informelles Pflegepotenzial bei Älteren in Deutschland - Ergebnisse einer bevölkerungsrepräsentativen Befragung. Z Gerontol Geriatr. 2017. p. 1-7.

3. Hajek A, König H-H. Informal Caregiving and Subjective Well-Being: Evidence of a Population-Based Longitudinal Study of Older Adults in Germany. J Am Med Dir Assoc. 2016;17(4):300-5.

4. Hajek A, König HH. The role of flexible goal adjustment in the effect of informal caregiving on depressive symptoms: Evidence of a large population-based longitudinal study in Germany from 2002 to 2011. Qual Life Res. 2017;26(2):419-27.

5. Rafnsson SB, Shankar A, Steptoe A. Informal caregiving transitions, subjective well-being and depressed mood: Findings from the English Longitudinal Study of Ageing. Aging Ment Health. 2017;21(1):104-12.

6. Bray GA. Medical consequences of obesity. J Clin Endocrinol Metabolism. 2004:89(6):2583-9.

7. Warburton DE, Nicol CW, Bredin SS. Health benefits of physical activity: the evidence. Can Med Assoc J. 2006;174(6):801-9.

8. Do EK, Cohen SA, Brown MJ. Socioeconomic and demographic factors modify the association between informal caregiving and health in the Sandwich Generation. BMC Public Health. 2014;14(1):1. 
9. Kusano CT, Bouldin ED, Anderson LA, McGuire LC, Salvail FR, Simmons KW, Andresen EM. Adult informal caregivers reporting financial burden in Hawaii, Kansas, and Washington: results from the 2007 Behavioral Risk Factor Surveillance System. Disability Health J. 2011;4(4):229-37.

10. Lee S, Colditz GA, Berkman LF, Kawachi I. Caregiving and risk of coronary heart disease in US women: a prospective study. Am J Prev Med. 2003;24(2): 113-9.

11. Hoffman GJ, Lee J, Mendez-Luck CA. Health Behaviors Among Baby Boomer Informal Caregivers. Gerontologist. 2012;52(2):219-30.

12. Hubert HB, Bloch DA, Oehlert JW, Fries JF. Lifestyle habits and compression of morbidity. J Gerontol A Biol Sci Med. 2002;57(6):M347-51.

13. Paffenbarger RS Jr, Hyde RT, Wing AL, Lee I-M, Jung DL, Kampert JB. The association of changes in physical-activity level and other lifestyle characteristics with mortality among men. N Engl J Med. 1993;328(8):538-45.

14. Klaus D, Engstler H, Mahne K, Wolff JK, Simonson J, Wurm S, Tesch-Römer C Cohort Profile: The German Ageing Survey (DEAS). Int J Epidemiol. 2017. p. 1-8.

15. Neller K. Kooperation und Verweigerung. Eine Non-Response-Studie [Cooperation and refusal: a non-response study]. ZUMA Nachrichten. 2005; 29(57):9-36.

16. Craig $C L$, Marshall $A L$, Sjorstrom M, Bauman $A E$, Booth $M L$, Ainsworth $B E$, Pratt M, Ekelund U, Yngve A, Sallis JF. International physical activity questionnaire: 12-country reliability and validity. Med Sci Sports Exerc. 2003; 35(8):1381-95.

17. Wurm S, Tomasik MJ, Tesch-Römer C. On the importance of a positive view on ageing for physical exercise among middle-aged and older adults: Cross-sectional and longitudinal findings. Psychol Health. 2010;25(1):25-42.

18. Hajek A, Brettschneider C, Lühmann D, Eisele M, Mamone S, Wiese B, Weyerer S, Werle J, Pentzek M, Fuchs A, et al. Effect of Visual Impairment on Physical and Cognitive Function in Old Age: Findings of a Population-Based Prospective Cohort Study in Germany. J Am Geriatr Soc. 2016;64(11):2311-6.

19. Hajek A, Lehnert $T$, Ernst $A$, Lange $C$, Wiese $B$, Prokein J, Weyerer $S$, Werle J, Pentzek M, Fuchs $A$, et al. Prevalence and determinants of overweight and obesity in old age in Germany. BMC Geriatr. 2015;15(1):83.

20. Sadrollahi A, Hosseinian M, Alavi NM, Khalili Z, Esalatmanesh S. Physical activity patterns in the elderly kashan population. Iran Red Crescent Med J. 2016;18(6):e25008.

21. Rabinovitz M, Pitlik SD, Leifer M, Garty M, Rosenfeld JB. Unintentional weight loss: a retrospective analysis of 154 cases. Arch Intern Med. 1986;146(1):186-7.

22. Wannamethee SG, Shaper AG, Lennon L. Reasons for intentional weight loss, unintentional weight loss, and mortality in older men. Arch Intern Med. 2005;165(9):1035-40.

23. Rice MC, Wicks MN, Martin JC. Health risk characteristics of black female informal caregivers on welfare. Clin Nurs Res. 2008;17(1):20-31.

24. Yiengprugsawan $V$, Harley D, Seubsman S-a, Sleigh AC. Physical and mental health among caregivers: findings from a cross-sectional study of Open University students in Thailand. BMC Public Health. 2012;12(1):1.

25. Hajek A, Brettschneider C, Ernst A, Posselt T, Wiese B, Prokein J, Weyerer S, Werle J, Fuchs A, Pentzek M. Longitudinal predictors of informal and formal caregiving time in community-dwelling dementia patients. Soc Psychiatry Psychiatr Epidemiol. 2016;51(4):607-16.

26. Radloff LS. The CES-D scale a self-report depression scale for research in the general population. Appl Psychol Meas. 1977;1(3):385-401.

27. Cohen S, Kamarck T, Mermelstein R. A global measure of perceived stress. J Health Soc Behav. 1983;24(4):385-96.

28. Istvan J, Zavela K, Weidner G. Body weight and psychological distress in NHANES I. Int J Obes Related Metabolic Disord. 1992;16(12):999-1003.

29. Palmer RM. Geriatric assessment. Med Clin North Am. 1999:83(6):1503-23.

30. Gorber SC, Tremblay M, Moher D, Gorber B. A comparison of direct vs. selfreport measures for assessing height, weight and body mass index: a systematic review. Obes Rev. 2007:8(4):307-26.

31. Schöllgen I, Huxhold O, Schmiedek F. Emotions and physical health in the second half of life: Interindividual differences in age-related trajectories and dynamic associations according to socioeconomic status. Psychol Aging. 2012;27(2):338-52

32. Zarit SH, Gaugler JE, Jarrott SE. Useful services for families: research findings and directions. Int J Geriatr Psychiatry. 1999:14(3):165-78.

\section{Submit your next manuscript to BioMed Central and we will help you at every step:}

- We accept pre-submission inquiries

- Our selector tool helps you to find the most relevant journal

- We provide round the clock customer support

- Convenient online submission

- Thorough peer review

- Inclusion in PubMed and all major indexing services

- Maximum visibility for your research

Submit your manuscript at www.biomedcentral.com/submit
Biomed Central 